NASA/TM-2001-210360

\title{
Durability Evaluation of Selected Solid Lubricating Films
}

Kazuhisa Miyoshi

Glenn Research Center, Cleveland, Ohio 
Since its founding, NASA has been dedicated to the advancement of aeronautics and space science. The NASA Scientific and Technical Information (STI) Program Office plays a key part in helping NASA maintain this important role.

The NASA STI Program Office is operated by Langley Research Center, the Lead Center for NASA's scientific and technical information. The NASA STI Program Office provides access to the NASA STI Database, the largest collection of aeronautical and space science STI in the world. The Program Office is also NASA's institutional mechanism for disseminating the results of its research and development activities. These results are published by NASA in the NASA STI Report Series, which includes the following report types:

- TECHNICAL PUBLICATION. Reports of completed research or a major significant phase of research that present the results of NASA programs and include extensive data or theoretical analysis. Includes compilations of significant scientific and technical data and information deemed to be of continuing reference value. NASA's counterpart of peerreviewed formal professional papers but has less stringent limitations on manuscript length and extent of graphic presentations.

- TECHNICAL MEMORANDUM. Scientific and technical findings that are preliminary or of specialized interest, e.g., quick release reports, working papers, and bibliographies that contain minimal annotation. Does not contain extensive analysis.

- CONTRACTOR REPORT. Scientific and technical findings by NASA-sponsored contractors and grantees.
- CONFERENCE PUBLICATION. Collected papers from scientific and technical conferences, symposia, seminars, or other meetings sponsored or cosponsored by NASA.

- SPECIAL PUBLICATION. Scientific, technical, or historical information from NASA programs, projects, and missions, often concerned with subjects having substantial public interest.

- TECHNICAL TRANSLATION. Englishlanguage translations of foreign scientific and technical material pertinent to NASA's mission.

Specialized services that complement the SII Program Office's diverse offerings include creating custom thesauri, building customized data bases, organizing and publishing research results ... even providing videos.

For more information about the NASA STI Program Office, see the following:

- Access the NASA STI Program Home Page at http://www.sti.nasa.goo

- E-mail your question via the Internet to help@sti.nasa.gov

- Fax your question to the NASA Access Help Desk at 301-621-0134

- Telephone the NASA Access Help Desk at 301-621-0390

- Write to:

NASA Access Help Desk

NASA Center for AeroSpace Information 7121 Standard Drive

Hanover, MD 21076 
NASA/TM-2001-210360

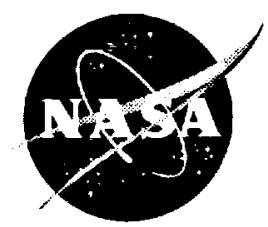

\section{Durability Evaluation of Selected Solid Lubricating Films}

Kazuhisa Miyoshi

Glenn Research Center, Cleveland, Ohio

Prepared for the

13th International Conference on Wear of Materials

sponsored by Elsevier Science

Vancouver, British Columbia, Canada, April 23-27, 2001

National Aeronautics and

Space Administration

Glenn Research Center 


\section{Acknowledgments}

The author thanks M. Iwaki, K. Gotoh, S. Obara, and K. Imagawa of the Tsukuba Space Center, Tsukuba, Ibaraki, Japan, for furnishing the selected solid lubricating films; and M. Murakawa, S. Watanabe, and S. Takeuchi of the Nippon Institute of Technology for depositing the PACVD DLC films.

Available from

NASA Center for Aerospace Information 7121 Standard Drive Hanover, MD 21076
National Technical Information Service 5285 Port Royal Road Springfield, VA 22100 


\title{
DURABILITY EVALUATION OF SELECTED SOLID LUBRICATING FILMS
}

\author{
Kazuhisa Miyoshi \\ National Aeronautics and Space Administration \\ Glenn Research Center \\ Cleveland, Ohio 44135
}

SUMMARY

An investigation was conducted to examine the coefficients of friction, wear rates, and durability of bonded molybdenum disulfide $\left(\mathrm{MoS}_{2}\right)$, magnetron-sputtered $\mathrm{MoS}_{2}$, ion-plated silver, ion-plated lead, magnetron-sputtered diamondlike carbon (MS DLC), and plasma-assisted, chemical-vapor-deposited DLC (PACVD DLC) films in sliding contact with 6-mm-diameter AISI $440 \mathrm{C}$ stainless steel balls. Unidirectional ball-on-disk sliding friction experiments were conducted with a load of $5.9 \mathrm{~N}$ and a sliding velocity of $0.2 \mathrm{~m} / \mathrm{s}$ at room temperature in three environments: ultrahigh vacuum (vacuum pressure, $7 \times 10^{-7} \mathrm{~Pa}$ ), humid air (relative humidity, $\sim 20$ percent), and dry nitrogen (relative humidity, $<1$ percent). The main criteria for judging the performance of the solid lubricating films were coefficient of friction and wear rate, which had to be less than 0.3 and on the order of $10^{-6} \mathrm{~mm}^{3} / \mathrm{N} \cdot \mathrm{m}$ or less, respectively. The bonded $\mathrm{MoS}_{2}$ and magnetron-sputtered $\mathrm{MoS}_{2}$ films met the criteria in all three environments. The ion-plated lead and silver films met the criteria only in ultrahigh vacuum but failed in humid air and dry nitrogen. The MS DLC and PACVD DLC films met the requirements in humid air and dry nitrogen but failed in ultrahigh vacuum.

\section{INTRODUCTION}

Solid lubricants designed for spacecraft applications must not only display desirable coefficients of friction ( 0.001 to 0.3 ) but also maintain good durability in different environments, such as the atmosphere and high or ultrahigh vacuum. However, very little data are available on the tribological properties, particularly the actual wear rates, of solid lubricating films in different environments. The tribological properties of dry, solid lubricating films vary with the environment, possessing a Jekyll-and-Hyde character.

For many years it has been known that molybdenum disulfide $\left(\mathrm{MoS}_{2}\right)$, silver, lead, and carbon have outstanding lubricating properties. These materials are at the same time old lubricants and also the newest durable lubricants. The technology of solid lubrication has advanced rapidly in the past four decades, conforming primarily to the needs of the automobile and aerospace industries (refs. 1 to 12). Recently, a number of new applications, such as microelectromechanical systems (MEMS), gears and bearings for long-term service in space mechanisms, lightweight gear and bearing systems, and piston rings for low-heat-rejection engines, have arisen that have prompted renewed interest in solid lubrication. The new requirements are primarily long-term life and broad-temperature-range capability of solid lubricating coatings. However, the MEMS industry confronts significant adhesion, friction, and wear problems in manufacturing and actual use. New solid lubricants and their coating technologies are needed to meet these requirements and solve these problems.

Compiling manufacturers' standard test results for a number of lubricant formulations can aid mechanism design engineers (i.e., users) in selecting the best lubricant for an application. However, such data can at best only narrow the field to a specific class of lubricant. Deciding on the optimum lubricant formulation for a specific application requires more custom-design, element, component, and full-scale testing. However, after the optimum lubricant has been chosen, such standard tests can also be useful for quality control. This is especially important during a long space program, where satellites or launch vehicles are built over a period of years during which lubricant formulations and film application procedures might undergo change. For solid lubricant films the end user should request that standard test coupons be coated along with the actual parts. Testing of each lubricant batch will ensure that the manufacturing quality remains constant throughout the life of the program. 
The objective of this study was to evaluate friction and wear properties, such as coefficient of friction, wear rate (dimensional wear coefficient), and endurance life, of selected solid lubricating films in three environments. Six types of newly developed, affordable, dry, solid film lubricant were evaluated: a bonded $\mathrm{MoS}_{2}$, a magnetronsputtered $\mathrm{MoS}_{2}$, an ion-plated silver, an ion-plated lead, a magnetron-sputtered diamondlike carbon (MS DLC), and a plasma-assisted, chemical-vapor-deposited diamondlike carbon (PACVD DLC). Some earlier work on the films is reported in the references (refs. 13 to 15 ).

\section{EXPERIMENTAL MATERIALS—SELECTED SOLID LUBRICATING FILMS}

Three specimens of four film types, bonded $\mathrm{MoS}_{2}$, magnetron-sputtered $\mathrm{MoS}_{2}$, ion-plated silver, and ion-plated lead, were produced on American Iron and Steel Institute (AISI) 440C stainless steel disk substrates. Three specimens of two film types, MS DLC and PACVD DLC, were produced on silicon wafers attached to the $440 \mathrm{C}$ stainless steel disks. Characteristics of the six types of solid film lubricant are presented in table I.

\section{Molybdenum Disulfide Films}

Molybdenum disulfide is a versatile and useful solid lubricant (refs. 1 to 3 ). Bonded films are much more readily available than sputtered films, but sputtered films are easy to incorporate in precision bearing systems. In this study both bonded and magnetron-sputtered $\mathrm{MoS}_{2}$ films were evaluated. As shown in table I, the bonded $\mathrm{MoS}_{2}$ films were relatively rough, having centerline-average roughness $R_{a}$ of $1.2 \mu \mathrm{m}$, and the magnetron-sputtered $\mathrm{MoS}_{2}$ films were relatively smooth, having $R_{a}$ in the range of $32 \mathrm{~nm}$. The bonded films were 10 times thicker than the sputtered films.

\section{Silver and Lead Films}

Soft metal films can be deposited as lubricating films on hard substrates by conventional electroplating or by physical vapor deposition methods, such as evaporation, vacuum sputtering, and ion plating. Ion plating and vacuum sputtering permit close control of film deposition and thickness and can provide good adhesion to the substrate (ref. 5). In this study ion-plated silver and ion-plated lead films (refs. 13 and 14) were evaluated. These films were relatively smooth, having $R_{a}$ of 30 and $98 \mathrm{~nm}$, respectively, and were $\sim 0.5 \mu \mathrm{m}$ thick and uniform.

\section{Diamondlike Carbon Films}

A new category of solid lubricants and lubricating films, diamond and related hard materials, is growing. Particularly, commercial interest in mechanical parts and components coated with diamondlike carbon (DLC) is continuously expanding. The cost is affordable and generally similar to that of carbide or nitride films deposited by chemical or physical vapor deposition (CVD and PVD) techniques. The surface smoothness, high hardness, low coefficient of friction, low wear rate, and chemical inertness of DLC coatings and films, along with little restriction of geometry and size, make them well suited for applications as solid lubricants combating wear and friction.

Magnetron-sputtered (MS) DLC and plasma-assisted (PA) CVD DLC films were evaluated. These films were relatively smooth, having $R_{a}$ of 43 and $29 \mathrm{~nm}$, respectively, and were $\sim 2$ to $5 \mu \mathrm{m}$ thick and uniform. The MS DLC films had a multilayer structure and were prepared by using two chromium targets, six tungsten carbide (WC) targets, and methane $\left(\mathrm{CH}_{4}\right)$ gas. The multilayer film comprised 20- to 50-nm-thick, alternating layers of WC and carbon. The Vickers hardness number was $\sim 1000$. The PACVD DLC films were prepared by using radiofrequency plasma and consisted of two layers, an $\sim 2-\mu \mathrm{m}$-thick DLC top layer on an $\sim 2-\mu \mathrm{m}$-thick silicon-DLC underlayer. The DLC top layer was deposited by using $\mathrm{CH}_{4}$ gas at a total pressure of $8 \mathrm{~Pa}$ with a power of 1800 to $2000 \mathrm{~W}$ at -750 to $-850 \mathrm{~V}$ for $120 \mathrm{~min}$. The silicon-containing DLC underlayer was deposited by using a mixture of $\mathrm{CH}_{4}$ and tetramethylsilane $\left(\mathrm{C}_{4} \mathrm{H}_{12} \mathrm{Si}\right)$ gases. The ratio of the concentration of $\mathrm{CH}_{4}$ and $\mathrm{C}_{4} \mathrm{H}_{12} \mathrm{Si}$ used was $90: 18\left(\mathrm{std} \mathrm{cm}^{3} / \mathrm{min}\right.$ ) at a total pressure of $10 \mathrm{~Pa}$ with a power of 1800 to $2000 \mathrm{~W}$ at -850 to $-880 \mathrm{~V}$ for $60 \mathrm{~min}$. The Vickers hardness number was 1600 to 1800 . 


\section{EXPERIMENTAL PROCEDURE}

The friction and wear properties of the selected solid lubricating films were examined in ultrahigh vacuum $\left(7 \times 10^{-7} \mathrm{~Pa}\right.$ ), in humid air at a relative humidity of $\sim 20$ percent, and in dry nitrogen at a relative humidity of $<$ I percent. Unidirectional ball-on-disk sliding friction experiments were conducted with 6-mm-diameter AISI $440 \mathrm{C}$ stainless steel balls in sliding contact with the solid lubricating films at room temperature in each environment. The disks were regular octahedrons $19 \mathrm{~mm}$ wide across the flats and $3 \mathrm{~mm}$ thick. As the disk rotated, the ball scribed a circular wear track on the flat disk surface. The assembly on which the disk specimen was mounted permits rotation at various track diameters, ranging from 5 to $16 \mathrm{~mm}$ in this investigation. The $440 \mathrm{C}$ balls (grade 10) used were smooth, having $R_{a}$ of $6.8 \mathrm{~nm}$ with a standard deviation of $1.8 \mathrm{~nm}$. The Vickers microhardness at 0.49 to $4.9 \mathrm{~N}$ for the $440 \mathrm{C}$ balls was $8.7 \mathrm{GPa}$.

Three to five sliding friction experiments were conducted on each film type in each environment. All experiments were performed at a load of $5.9 \mathrm{~N}$ and a sliding velocity of $0.2 \mathrm{~m} / \mathrm{s}$. The steady-state coefficients of friction, wear rates (dimensional wear coefficients), and endurance lives for the solid lubricating films and the wear rates for the 440C stainless steel balls were obtained by averaging the data taken from a minimum of three experiments at various track diameters on three specimens of each film type in each environment. The resultant solid lubricating films and their wear surfaces were characterized by scanning electron microscopy (SEM), energy-dispersive $x$-ray spectroscopy (EDX), and surface profilometry. SEM and EDX were used to determine the morphology and elemental composition of wear surfaces and wear debris. The sampling depth of EDX for elemental information ranged between 0.5 and $1 \mu \mathrm{m}$ in this study. Surface profilometry was used to determine the surface morphology, roughness, and wear of the films.

\section{EXPERIMENTAL RESULTS AND DISCUSSION}

\section{Comparison of Steady-State Coefficients of Friction and Wear Rates}

Figures 1 to 3 summarize the average values of the steady-state coefficients of friction, the film wear rates (dimensional wear coefficients), and the ball wear rates after sliding contact in all three environments: ultrahigh vacuum, humid air, and dry nitrogen. The data presented in the figures reveal the marked differences in friction and wear resulting from the environmental conditions and the solid lubricating film materials.

Ultrahigh vacuum.-As shown in figure 1 , in sliding contact with $440 \mathrm{C}$ stainless steel balls in ultrahigh vacuum, the bonded $\mathrm{MoS}_{2}$ films had the lowest coefficient of friction, lowest film wear rate, and lowest ball wear rate. The MS MoS 2 films also had low coefficient of friction, low film wear rate, and low ball wear rate, similar to those for the bonded $\mathrm{MoS}_{2}$. The film and ball wear rates in ultrahigh vacuum were in ascending order: bonded $\mathrm{MoS}_{2}<\mathrm{MS} \mathrm{MoS}_{2}<$ ion-plated silver < ion-plated lead < PACVD DLC < MS DLC. The coefficients of friction followed a similar ascending order. The MS DLC films had the highest coefficient of friction, the highest film wear rate, and the highest ball wear rate in ultrahigh vacuum.

Humid air.-As shown in figure 2, in sliding contact with 440C stainless steel balls in humid air, the PACVD DLC film had the lowest coefficient of friction, lowest film wear rate, and lowest ball wear. The bonded $\mathrm{MoS}_{2}$, MS MoS 2 , and MS DLC films generally had low coefficients of friction, low film wear rates, and low ball wear rates, similar to those for the PACVD DLC. The wear rates of the solid lubricating films in humid air were in ascending order: PACVD DLC $<$ MS DLC $<M S \mathrm{MoS}_{2}<$ bonded $\mathrm{MoS}_{2}<$ ion-plated lead < ion-plated silver. The coefficients of friction and wear rates of the balls followed a similar ascending order. The ion-plated silver films had the highest coefficient of friction, highest film wear rate, and highest ball wear rate in humid air.

Dry nitrogen.-As shown in figure 3 , in sliding contact with $440 \mathrm{C}$ stainless steel balls in dry nitrogen, the MS $\mathrm{MoS}_{2}$ films had the lowest coefficient of friction. The bonded $\mathrm{MoS}_{2}$, MS DLC, and PACVD DLC films had low coefficients of friction, low film wear rates, and low ball wear rates. However, the ion-plated silver and ionplated lead films had high friction and high wear. The wear rates of the solid lubricating films in dry nitrogen were in ascending order: PACVD DLC $<\mathrm{MS} \mathrm{MoS}_{2}<$ bonded $\mathrm{MoS}_{2}<\mathrm{MS}$ DLC < ion-plated lead < ion-plated silver. The coefficients of friction and wear rates of the balls followed a similar ascending order. 
The endurance (sliding wear) life of the solid lubricating films deposited on $440 \mathrm{C}$ stainless steel disks was determined to be the number of passes at which the coefficient of friction rose to 0.30 in a given environment. The average values of sliding endurance lives, presented in figures 4 to 6 , varied with the environment and the type of solid lubricating film.

Ultrahigh vacuum.-As shown in figure 4 , in sliding contact with $440 \mathrm{C}$ stainless steel balls in ultrahigh vacuum, the bonded $\mathrm{MoS}_{2}$ films had the longest endurance life, over 1 million passes. The endurance lives of the solid lubricating films in ultrahigh vacuum were in descending order: bonded $\mathrm{MoS}_{2}>$ ion-plated silver $>\mathrm{MS} \mathrm{MoS}_{2}$ $>$ ion-plated lead > PACVD DLC > MS DLC.

Humid air.-As shown in figure 5 , in sliding contact with $440 \mathrm{C}$ stainless steel balls in humid air, both PACVD DLC and MS DLC had the longest endurance lives, over 1 million passes. The endurance lives of the solid lubricating films in humid air were in descending order: PACVD DLC $>$ MS DLC $>\mathrm{MS} \mathrm{MoS}_{2}>$ bonded $\mathrm{MoS}_{2}>$ ion-plated lead > ion-plated silver.

Dry nitrogen.-As shown in figure 6 , in sliding contact with $440 \mathrm{C}$ stainless steel balls in dry nitrogen, the bonded $\mathrm{MoS}_{2}, \mathrm{MS} \mathrm{MoS}_{2}$, and PACVD DLC films had the longest endurance lives, over 1 million passes. The endurance lives of the solid lubricating films in dry nitrogen were in descending order: bonded $\mathrm{MoS}_{2}>\mathrm{MS} \mathrm{MoS}_{2}>$ PACVD DLC > MS DLC > ion-plated lead > ion-plated silver.

\section{Sliding Wear Behavior, Wear Debris, and Transferred Wear Fragments}

Adhesion and plastic deformation played important roles in the friction and sliding wear of the selected solid lubricating films in sliding contact with the $440 \mathrm{C}$ stainless steel balls in ultrahigh vacuum, humid air, and dry nitrogen (refs. 13 to 15). The worn surfaces of both the films and the balls contained wear debris particles. Examination of the surface morphology and compositions of the worn surfaces by SEM and EDX provided detailed information about plastic deformation of the solid lubricating films, wear debris, and transferred wear fragments produced during sliding in all three environments. Marked plastic deformation occurred in the six solid lubricating films. Smeared, agglomerated wear debris accumulated around the contact borders, particularly at the rear end of the wear scars. All sliding involved adhesive transfer of materials.

Bonded $\mathrm{MOS}_{2}$.-The $44 \overline{0} \mathrm{C}$ stainless steel balls left transferred steel wear fragments in the wear tracks on the bonded $\mathrm{MoS}_{2}$ films in all three environments (ref. 13). During sliding the relatively coarse asperities of the bonded $\mathrm{MoS}_{2}$ films were deformed plastically, and the tips of the asperities were flattened under load. The ball wear scars contained transferred $\mathrm{MoS}_{2}$ wear fragments. Wear fragments of $\mathrm{MoS}_{2}$ and steel usually adhered to the counterpart surface or came off in loose form. Another form of adhesive $\mathrm{MoS}_{2}$ transfer was found in sliding wear. SEM and EDX showed that a thin $\mathrm{MoS}_{2}$ layer (or sheet) was generated over the entire ball wear scars in all three environments.

Magnetron-sputtered $\mathrm{MoS}_{2}$. - The $440 \mathrm{C}$ stainless steel balls left transferred steel wear fragments in the wear tracks on the $\mathrm{MS} \mathrm{MoS}_{2}$ films in all three environments (ref. 13). The fine asperities of the sputtered $\mathrm{MoS}_{2}$ films were flattened and elongated in the sliding direction by plastic deformation, revealing a burnished appearance. The ball wear scars contained transferred $\mathrm{MoS}_{2}$ wear fragments. A thin $\mathrm{MoS}_{2}$ layer was also generated over the entire ball wear scars.

According to the elemental concentrations, in ultrahigh vacuum much less transfer occurred between the films and the balls and vice versa with $\mathrm{MS} \mathrm{MoS}_{2}$ than with bonded $\mathrm{MoS}_{2}$. In both humid air and dry nitrogen, however, more stainless steel transferred to the sputtered $\mathrm{MoS}_{2}$ films than to the bonded $\mathrm{MoS}_{2}$ films, although much less bonded $\mathrm{MoS}_{2}$ transferred to the steel. A thin $\mathrm{MoS}_{2}$ layer was also generated over the entire ball wear scars in humid air and dry nitrogen.

Ion-plated silver.-The $440 \mathrm{C}$ stainless steel balls left a small amount of transferred steel wear fragments in the wear tracks on the ion-plated silver films in all three environments (ref. 13). The fine asperities of the ion-plated silver films were flattened and elongated in the sliding direction by plastic deformation, revealing a burnished appearance. Severe plastic deformation and shearing occurred in the silver films during sliding.

According to the elemental concentrations, after sliding in ultrahigh vacuum the entire ball wear scar contained thick transferred layers (or sheets) of silver, and plate-like silver debris particles were deposited at the edges of the film wear track. In contrast, after sliding in humid air the ball wear scar contained an extremely small amount of transferred silver particles. This result suggests that oxidation of silver during sliding in humid air may prevent large silver transfer. However, plate-like silver wear debris was deposited at the edges of the film wear track in humid air. 
After sliding in dry nitrogen the ball wear scar contained transferred silver plates and particles, and plate-like silver wear debris was deposited at the edges of the film wear track. Severe plastic deformation and shearing occurred in the silver film during sliding in dry nitrogen.

Ion-plated lead.- The $440 \mathrm{C}$ stainless steel balls left a small amount of transferred steel wear fragments in the wear tracks on the ion-plated lead films in all three environments (ref. 14). The fine asperities of the ion-plated lead films were flattened and elongated in the sliding direction by plastic deformation, revealing a burnished appearance. Severe plastic deformation and shearing occurred in the lead film during sliding.

According to the elemental concentrations, after sliding in ultrahigh vacuum the entire ball wear scar contained thick transferred layers (or sheets) of lead. Plate-like lead debris was found at the edges of the film wear track. In contrast, after sliding in humid air the ball wear scar contained an extremely small amount of transferred lead debris particles. This result suggests that oxidation of lead, like silver oxidation, during sliding in humid air may prevent large lead transfer. However, plate-like lead wear debris was deposited at the edges of the film wear track in humid air. After sliding in dry nitrogen the ball wear scar contained transferred lead plates and particles, and plate-like lead wear debris was deposited at the edges of the film wear track.

Magnetron-sputtered DLC.-With MS DLC films sliding involved generation of fine wear debris particles and agglomerated wear debris and transfer of the worn materials in all three environments (ref. 15).

According to the elemental concentrations, after sliding in ultrahigh vacuum the $440 \mathrm{C}$ stainless steel ball left a roughened worn surface and a small amount of transferred steel fragments in the wear track on the MS DLC film. The ball wear scar contained fine steel particles and a small amount of transferred DLC fragments. The wear mechanism was that of small fragments chipping off the DLC surface.

After sliding in humid air the $440 \mathrm{C}$ stainless steel ball left a small amount of transferred steel fragments in the wear track on the MS DLC film. The fine asperities of the MS DLC film were flattened and elongated in the sliding direction by plastic deformation, revealing a burnished appearance. The entire ball wear scar contained transferred patches and thick transferred layers (or sheets) of MS DLC. Plate-like DLC wear debris was also deposited at the edges of the wear scar. Severe plastic deformation and shearing occurred in the DLC film during sliding in humid air.

After sliding in dry nitrogen the $440 \mathrm{C}$ stainless steel ball left an extremely small amount of transferred steel wear debris in the wear track on the MS DLC film. In addition, smeared, agglomerated DLC wear debris was deposited on the film. The fine asperities of the MS DLC film were flattened and elongated in the sliding direction by plastic deformation, revealing a burnished appearance. The ball wear scar contained transferred DLC wear debris.

Plasma-assisted. chemical-vapor-deposited DLC.-With PACVD DLC films, like MS DLC films, sliding involved generation of fine wear debris particles and agglomerated wear debris and transfer of the worn materials in all three environments (ref. 15).

According to the elemental concentrations, after sliding in ultrahigh vacuum the $440 \mathrm{C}$ stainless steel ball left smeared, agglomerated DLC wear debris and a small amount of transferred steel fragments in the film wear track. The ball wear scar contained fine steel particles and large smeared, agglomerated patches containing transferred DLC fragments. The wear mechanism was adhesive, and plastic deformation played a role in the burnished appearance of the smeared, agglomerated wear debris.

After sliding in humid air the $440 \mathrm{C}$ stainless steel ball left a small amount of transferred steel fragments in the film wear track. The fine asperities of the PACVD DLC film were flattened and elongated in the sliding direction by plastic deformation, revealing a burnished appearance. The smooth ball wear scar contained an extremely small amount of transferred DLC wear debris.

After sliding in dry nitrogen the $440 \mathrm{C}$ stainless steel ball left DLC wear debris, micropits, and an extremely small amount of transferred steel wear debris in the wear track on the PACVD DLC film. The fine asperities of the film were flattened and elongated in the sliding direction by plastic deformation, revealing a burnished appearance. The ball wear scar contained fine grooves in the sliding direction, steel wear debris, and a small amount of transferred DLC wear debris.

\section{SUMMARY OF REMARKS}

Recently developed, dry, solid film lubricants were evaluated for solid lubrication applications by conducting unidirectional sliding friction experiments with bonded molybdenum disulfide $\left(\mathrm{MoS}_{2}\right)$ films, magnetron-sputtered $\mathrm{MoS}_{2}$ films, ion-plated silver films, ion-plated lead films, magnetron-sputtered diamondlike carbon (DLC) films, and plasma-assisted, chemical-vapor-deposited DLC films in contact with AISI 440C stainless steel balls in ultra- 
high vacuum, in humid air, and in dry nitrogen. When the main criteria for judging the performance of the dry solid lubricating films were coefficient of friction and wear rate, which had to be less than 0.3 and $10^{-6} \mathrm{~mm}^{3} / \mathrm{N} \cdot \mathrm{m}$, respectively, the following remarks can be made:

1. Bonded $\mathrm{MoS}_{2}$ and magnetron-sputtered $\mathrm{MoS}_{2}$ films met both criteria in all three environments. Also, the wear rates of the counterpart $440 \mathrm{C}$ stainless steel balls met that criterion in all three environments.

2. In ultrahigh vacuum the coefficient of friction and endurance (wear) life of bonded $\mathrm{MoS}_{2}$ films were superior to those of all the other dry, solid film lubricants.

3. Ion-plated silver films met both criteria only in ultrahigh vacuum, failing in humid air and in dry nitrogen, where the film and ball wear rates were higher than the criterion.

4. Ion-plated lead films met both criteria only in ultrahigh vacuum, failing in humid air and in dry nitrogen, where the coefficients of friction were greater than the criterion. Both the lead film wear rate and the ball wear rate met that criterion in all three environments.

5. MS DLC and PACVD DLC films met the criteria in humid air and in dry nitrogen, failing in ultrahigh vacuum, where the coefficients of friction were greater than the criterion.

6. Adhesion and plastic deformation played important roles in the friction and wear of all the solid lubricating films in contact with $440 \mathrm{C}$ stainless steel balls in the three environments. All sliding involved adhesive transfer of materials: transfer of solid lubricant wear debris to the counterpart $440 \mathrm{C}$ stainless steel, and transfer of $440 \mathrm{C}$ stainless steel wear debris to the counterpart solid lubricant.

\section{REFERENCES}

1. A.R. Lansdown, Lubrication and Lubricant Selection-A Practical Guide, Mechanical Engineering Publications, London, 1996.

2. M.E. Campbell, J.B. Loser, and E. Sneegas, Solid Lubricants, NASA SP-5059, 1966.

3. M.E. Campbell, Solid Lubricants-A Survey, NASA SP-5059(01), 1972.

4. F.J. Clauss, Solid Lubricants and Self-Lubricating Solids, Academic Press, New York, 1972.

5. J.K. Lancaster, Solid Lubricants, in CRC Handbook of Lubrication, Vol. II, E.R. Booser, ed., CRC Press, Boca Raton, FL, 1984, pp. 269-290.

6. M.J. Todd and R.H. Bentall, Lead Film Lubrication in Vacuum, Proceedings of the ASLE 2nd International Conference on Solid Lubrication, SP-6, 1978, pp. 148-157.

7. J.R. Lince and P.D. Fleischauer, Solid Lubrication for Spacecraft Mechanisms, Aerospace Corp. Report TR-97(8565)-4, 1997.

8. E.W. Roberts, Thin Solid-Lubricant Films in Space, in Flight-Vehicle Materials, Structures, and Dynamics, Vol. 4, R.L. Fusaro and J.D. Achenbach, eds., ASME, New York, 1993, pp. 113-132.

9. H.O. Pierson, Handbook of Carbon, Graphite, Diamond, and Fullerenes: Properties, Processing, and Applications, Noyes Publications, Park Ridge, NJ, 1993.

10. A.P. Molloy and A.M. Dionne, eds., World Markets, New Applications, and Technology for Wear and Superhard Coatings, Gorham Advanced Materials, Inc., Gorham, ME, 1998.

11. K. Miyoshi, M. Murakawa, S. Watanabe, S. Takeuchi, and R.L.C. Wu, Tribological Characteristics and Applications of Superhard Coatings: CVD Diamond, DLC, and c-BN, Proceedings of Applied Diamond Conference/Frontier Carbon Technology Joint Conference 1999, Tsukuba, Japan, pp. 268-273. (Also NASA/TM-1999-209189, 1999.)

12. K. Miyoshi, New Diamond and Frontier Carbon Technology, 9,6 (1999) pp. 381-394.

13. K. Miyoshi, M. Iwaki, K. Gotoh, S. Obara, and K. Imagawa, Friction and Wear Properties of Selected Solid Lubricating Films, Part 1: Bonded and Magnetron-Sputtered Molybdenum Disulfide and Ion-Plated Silver Films, NASA/TM-1999-209088/PART 1, October 1999.

14. K. Miyoshi, M. Iwaki, K. Gotoh, S. Obara, and K. Imagawa, Friction and Wear Properties of Selected Solid Lubricating Films, Part 2: Ion-Plated Lead Films, NASA/TM-2000-209088/PART 2, May 2000.

15. K. Miyoshi, M. Iwaki, K. Gotoh, S. Obara, and K. Imagawa: Friction and Wear Properties of Selected Solid Lubricating Films, Part 3: Magnetron-Sputtered and Plasma-Assisted, Chemical-Vapor-Deposited Diamondlike Carbon Films, NASA/TM-2000-209088/PART 3, June 2000. 
TABLE 1.-CHARACTERISTICS OF SELECTED SOLID LUBRICATING FILMS [Substrate material, $440 \mathrm{C}$ stainless steel.]

\begin{tabular}{|c|c|c|c|c|c|}
\hline \multirow[t]{2}{*}{ Film } & \multirow[t]{2}{*}{ Film material } & \multirow[t]{2}{*}{$\begin{array}{c}\text { Film } \\
\text { thickness, } \\
\mu \mathrm{m}\end{array}$} & \multicolumn{2}{|c|}{$\begin{array}{c}\text { Film surface } \\
\text { roughness }^{\mathrm{a}}, \\
R_{a}, \\
\mathrm{~nm} \\
\end{array}$} & \multirow[t]{2}{*}{$\begin{array}{c}\text { Substrate } \\
\text { material }\end{array}$} \\
\hline & & & Mean & $\begin{array}{l}\text { Standard } \\
\text { deviation }\end{array}$ & \\
\hline Bonded $\mathrm{MoS}_{2}$ & $\begin{array}{l}\mathrm{MoS}_{2} \text {, polyimide- } \\
\text { imide, others } \\
\text { (proprietary blend) }\end{array}$ & $10 \pm 4$ & $1.2 \times 10^{3}$ & $2.4 \times 10^{2}$ & $\begin{array}{c}440 \mathrm{C} \\
\text { stainless steel }\end{array}$ \\
\hline MS MoS & $\mathrm{MoS}_{2}$ & $1.0 \pm 0.2$ & 32 & 40 & \\
\hline Ion-plated silver & Silver & $0.5 \pm 0.2$ & 30 & 3.2 & \\
\hline Ion-plated lead & Lead & 0.55 & 98 & 15 & $\nabla$ \\
\hline MS DLC & Carbon and WC & 2 to 3 & 43 & 5.1 & Silicon \\
\hline PACVD DLC & Carbon and $\mathrm{Si}$ & 3 to 5 & 29 & 3.2 & Silicon \\
\hline
\end{tabular}

${ }^{3}$ The centerline-average roughness $R_{a}$ was measured by using a cutoff of $1 \mathrm{~mm}$. 

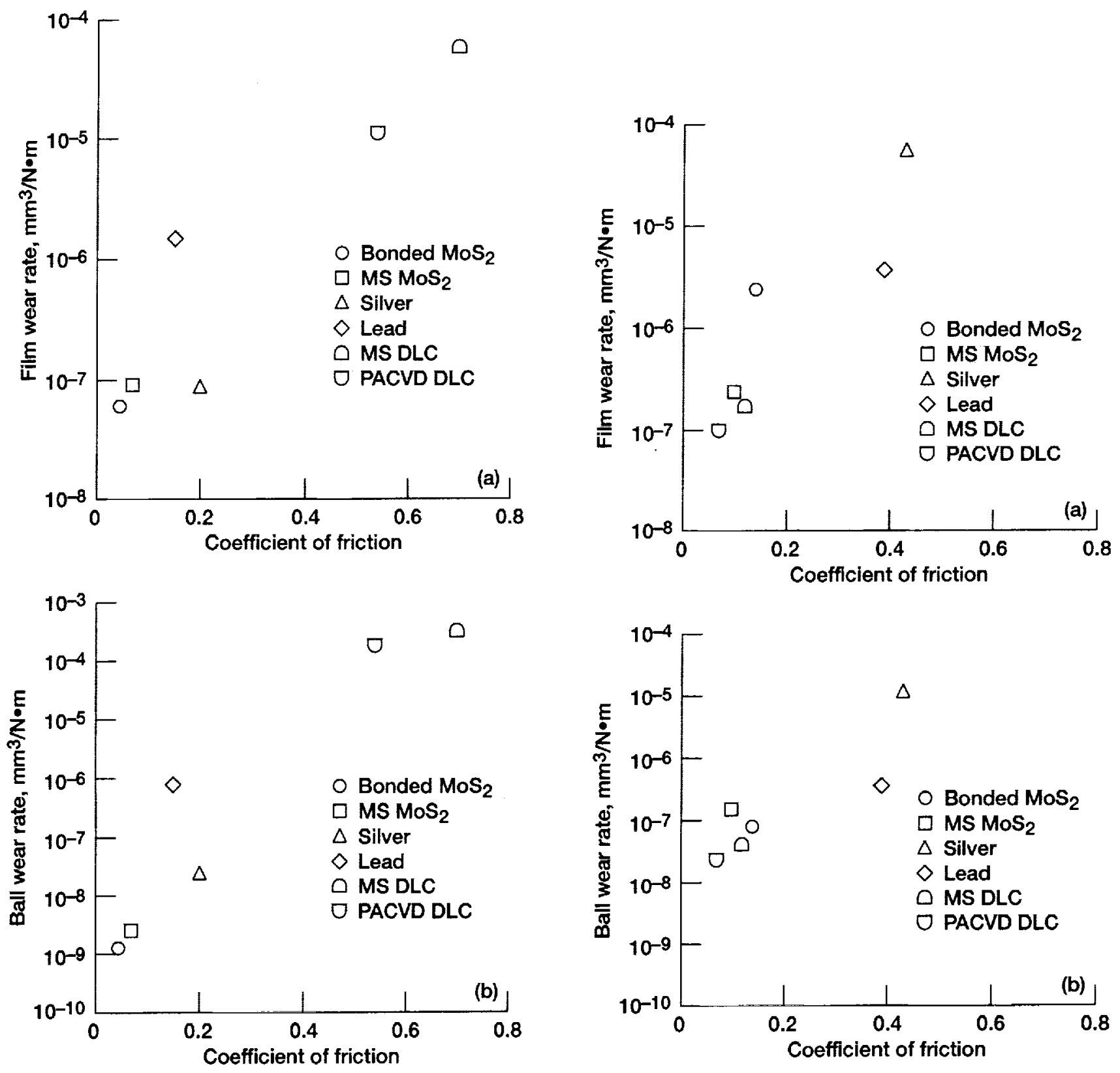

Figure 1.-Average values of steady-state (equilibrium) coefficients of friction and wear rates (dimensional wear coefficients) for solid lubricating films in sliding contact with $440 \mathrm{C}$ stainless steel balls in ultrahigh vacuum. (a) Film wear rate. (b) Ball wear rate.

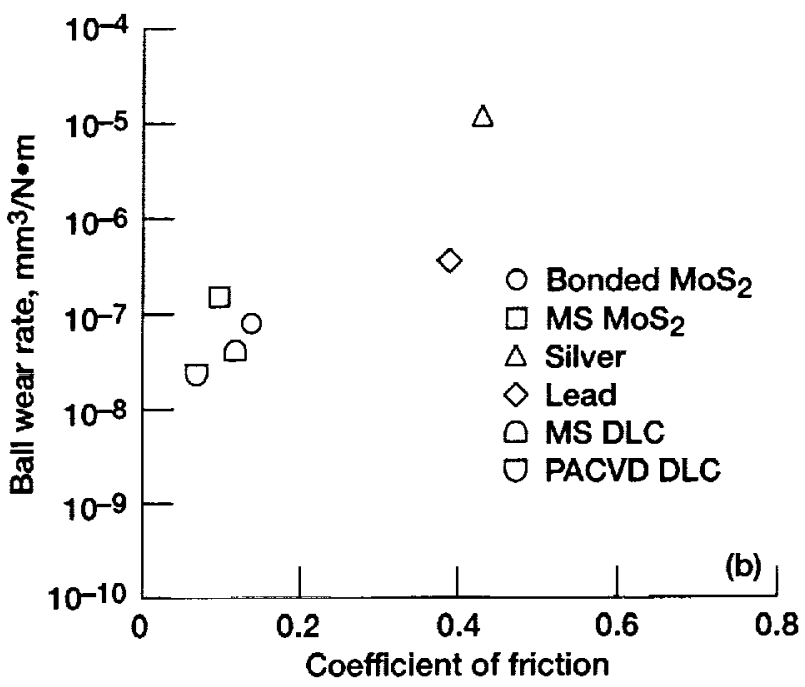

Figure 2.-Average values of steady-state (equilibrium) coefficients of friction and wear rates (dimensional wear coefficients) for solid lubricating films in sliding contact with $440 \mathrm{C}$ stainless steel balls in humid air. (a) Film wear rate. (b) Ball wear rate. 

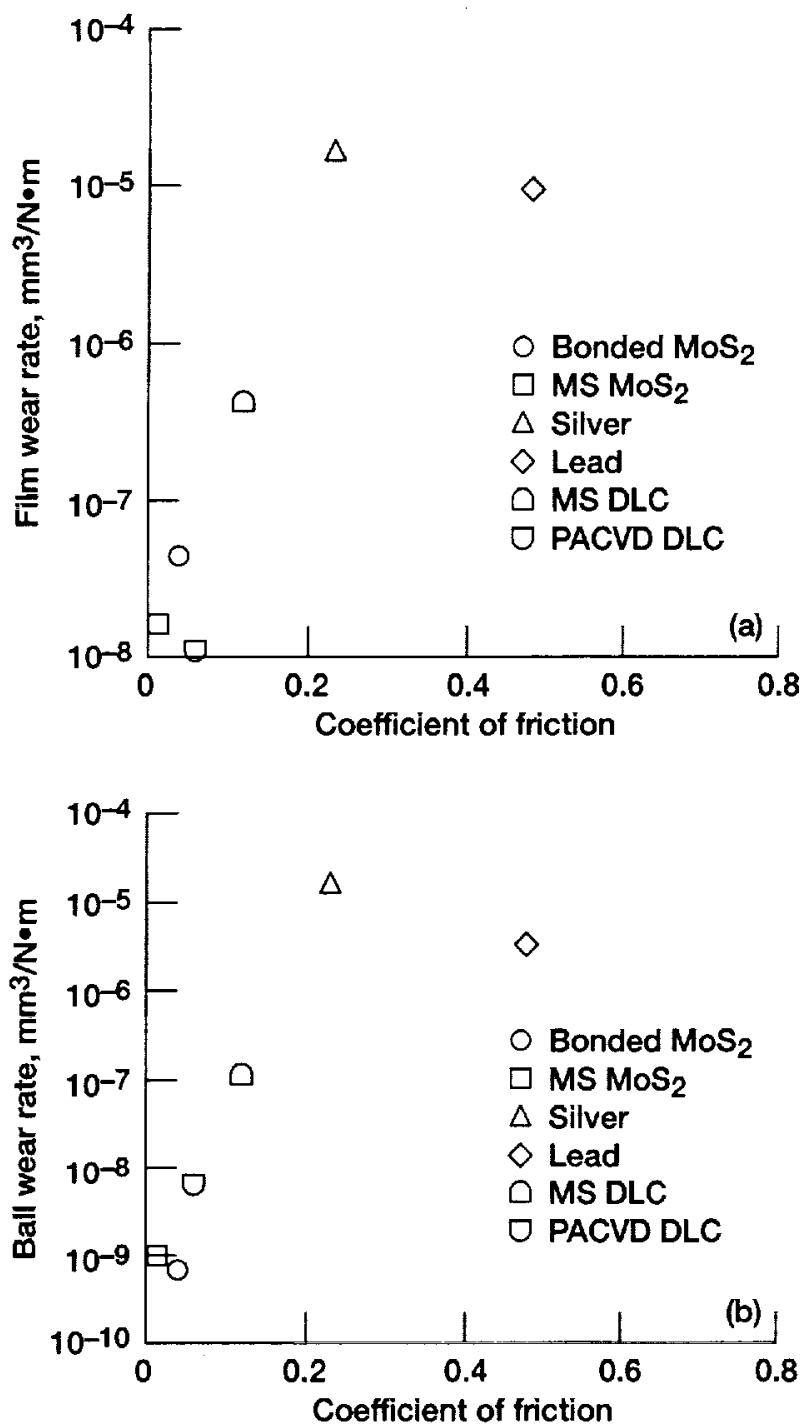

Figure 3.-Average values of steady-state (equilibrium) coefficients of friction and wear rates (dimensional wear coefficients) for solid lubricating films in sliding contact with $440 \mathrm{C}$ stainless steel balls in dry nitrogen. (a) Film wear rate. (b) Ball wear rate.

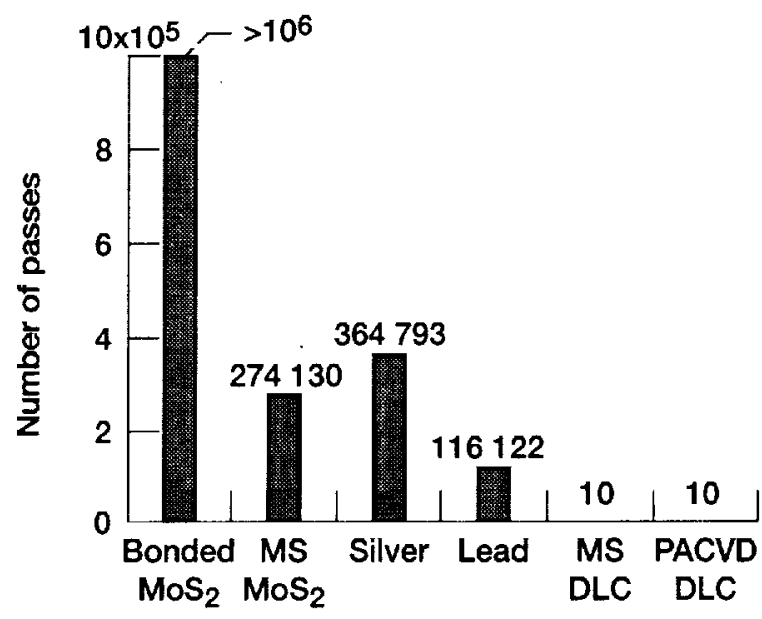

Figure 4.-Average values of endurance lives for solid lubricating films in sliding contact with $440 \mathrm{C}$ stainless steel balls in ultrahigh vacuum.

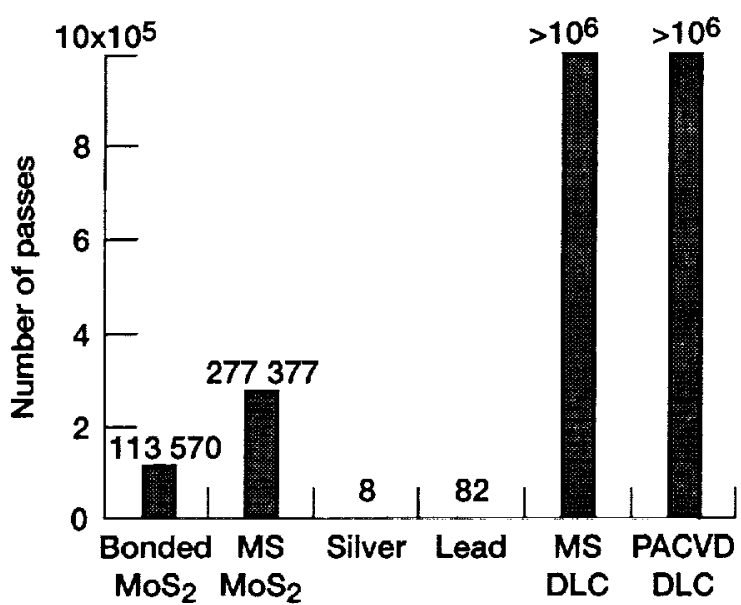

Figure 5.-Average values of endurance lives for solid lubricating films in sliding contact with $440 \mathrm{C}$ stainless steel balls in humid air.

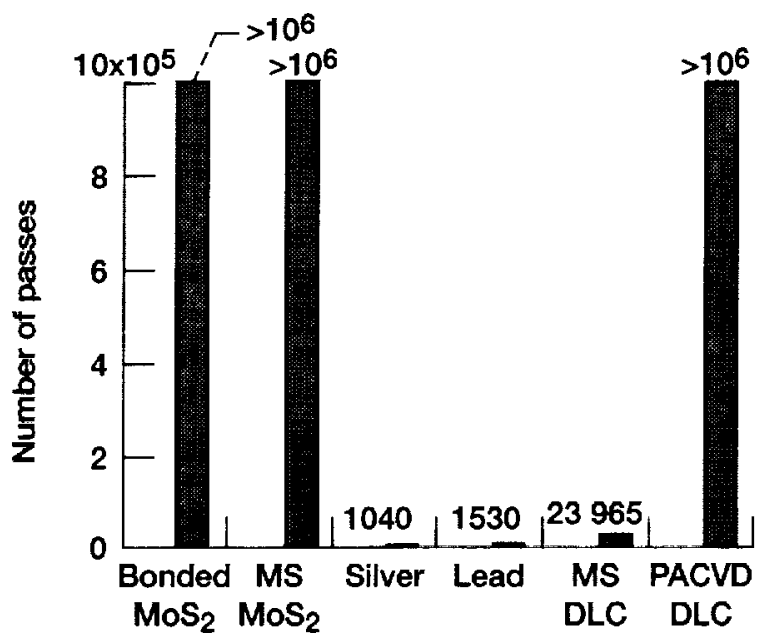

Figure 6.-Average values of endurance lives for solid lubricating films in sliding contact with $440 \mathrm{C}$ stainless steel balls in dry nitrogen. 
Davis Highway, Suite 1204, Artington, VA 22202-4302, and to the Office of Management and Budget, Papenwork Reduction Project (0704-0188), Washington, DC 20503

\begin{tabular}{|c|c|c|}
\hline 1. AGENCY USE ONLY (Leave blank) & $\begin{array}{r}\text { 2. REPORT DATE } \\
\text { May 2001 }\end{array}$ & $\begin{array}{l}\text { 3. REPOATT TYPE AND DATES COVERED } \\
\text { Technical Memorandum }\end{array}$ \\
\hline
\end{tabular}

4. TITLE AND SUBTITLE

Durability Evaluation of Selected Solid Lubricating Films
WU-297-60-00-00

8. PERFORMING ORGANIZATION REPORT NUMBER

E-12409

10. SPONSORING/MONITORING AGENCY REPORT NUMBER

NASA TM-2001-210360

National Aeronautics and Space Administration

Washington, DC 20546-0001

11. SUPPLEMENTARY NOTES

Prepared for the 13th International Conference on Wear of Materials sponsored by Elsevier Science, Vancouver, British Columbia, Canada, April 23-27, 2001. Responsible person, Kazuhisa Miyoshi, organization code 5160, 216-433-6078.

12a. DISTRIBUTION/AVAILABILITY STATEMENT

12b. DISTRIBUTION CODE

Unclassified - Unlimited

Subject Category: 27

Distribution: Nonstandard

Available electronically at http://gltrs.grc.nasa.gov/GLTRS

This publication is available from the NASA Center for AeroSpace Information, 301-621-0390.

13. ABSTRACT (MaxImum 200 words)

An investigation was conducted to examine the coefficients of friction, wear rates, and durability of bonded molybdenum disulfide $\left(\mathrm{MoS}_{2}\right)$, magnetron-sputtered $\mathrm{MoS}_{2}$, ion-plated silver, ion-plated lead, magnetron-sputtered diamondlike carbon (MS DLC), and plasma-assisted, chemical-vapor-deposited DLC (PACVD DLC) films in sliding contact with 6-mm-diameter AISI 440C stainless steel balls. Unidirectional ball-on-disk sliding friction experiments were conducted with a load of $5.9 \mathrm{~N}$ and a sliding velocity of $0.2 \mathrm{~m} / \mathrm{s}$ at room temperature in three environments: ultrahigh vacuum (vacuum pressure, $7 \times 10^{-7} \mathrm{~Pa}$ ), humid air (relative humidity, $\sim 20$ percent), and dry nitrogen (relative humidity, $<1$ percent). The main criteria for judging the performance of the solid lubricating films were coefficient of friction and wear rate, which had to be less than 0.3 and on the order of $10^{-6} \mathrm{~mm}^{3} / \mathrm{N} \cdot \mathrm{m}$ or less, respectively. The bonded $\mathrm{MoS}_{2}$ and magnetron-sputtered $\mathrm{MoS}_{2}$ films met the criteria in all three environments. The ion-plated lead and silver films met the criteria only in ultrahigh vacuum but failed in humid air and in dry nitrogen. The MS DLC and PACVD DLC films met the requirements in humid air and dry nitrogen but failed in ultrahigh vacuum.

\section{SUBJECT TERMS}

$\mathrm{MoS}_{2}$ films; Lead films; Silver films; DLC films; Materials

15. NUMBER OF PAGES

SECUAITY CLASSIFICATION OF REPORT

Unclassified
18. SECURITY CLASSIFICATION OF THIS PAGE

Unclassified
19. SECURITY CLASSIFICATION OF ABSTRACT Unclassified

NSN 7540-01-280-5500

15

\section{PRICE CODE}

20. LIMITATION OF ABSTRACT

Standard Form 298 (Rev. 2-89) Prescribed by ANSI Std. 239-18 298-102 